\title{
ESTIOLAMENTO DA PLANTA MATRIZ E USO DE ÁCIDO INDOLBUTÍRICO NO ENRAIZAMENTO DE ESTACAS DE GOIABEIRAS ${ }^{1}$
}

\author{
WALTER HENRIQUE DA COSTA JR ${ }^{2}$, JOÃO ALEXIO SCARPARE FILHO ${ }^{3}$, DÉBORA COSTA BASTOS ${ }^{4}$
}

\begin{abstract}
RESUMO - Este trabalho foi desenvolvido com o objetivo de verificar a influência do estiolamento em plantas matrizes de goiabeira, cultivares Rica e Kumagai, e da aplicação do ácido indolbutírico no enraizamento de estacas. O experimento foi conduzido em delineamento estatístico de blocos ao acaso, em fatorial 2 x 3, onde os fatores estudados foram concentração de AIB (0 e 2000 mg.L - $\left.^{-1}\right)$ e sombreamento ( 0 , 30 e 50\%). As estacas foram colocadas para enraizar em câmara de nebulização intermitente e após 60 dias, avaliou-se as seguintes características: porcentagem de estacas enraizadas, o número de raízes por estaca, a porcentagem de estacas mortas e de estacas com gemas brotadas. Concluiu-se que as cultivares testadas possuem diferentes capacidades de enraizamento. Para a cultivar Kumagai, a utilização de $30 \%$ de sombreamento proporcionou os melhores resultados de enraizamento. Para a cultivar Rica, a utilização de 30\% de sombreamento na planta matriz ou a aplicação de $2000 \mathrm{mg} . \mathrm{L}^{-1}$ de AIB na estaca proporcionaram as maiores percentagens de estacas enraizadas. A utilização de ácido indolbutírico aumentou o número de raízes formadas em estacas de goiabeira.
\end{abstract}

Termos para indexação: IBA, propagação, Psidium guajava L., sombreamento

\section{STOCK PLANT SHADING AND INDOLBUTYRIC ACID IN THE ROOTING OF Psidium guajava L.}

\begin{abstract}
This research was carried with the aim of verify the shading influence in the stock plants of two guava cultivars and the use of indolbutyric acid in the rooting of cuttings. The experimental design was in randomized blocks, $2 \times 3$ factorial, the factors studied were the application of IBA ( 0 e $\left.2000 \mathrm{mg} . \mathrm{L}^{-1}\right)$ and the shading of stock plants with the percentage of 30 and $50 \%$, as stock plants growing with plenty of sun. The cuttings were put in an intermittent mist chamber in a green house. After 60 days, the percentage of rooted cuttings were avaliated, as the number of roots per cutting, the percentage of dead cuttings and the percentage of shooted cuttings. It is concluded that the cultivars Rica and Kumagai have different rooting capabilities. The use of $30 \%$ of shading in the cuttings for Kumagai provided the best results of rooting. The use of $30 \%$ of shading or the application of $2000 \mathrm{mg} . \mathrm{L}^{-1} \mathrm{IBA}$ in the cuttings for Rica provided the best percentages of rooting. The use of indolbutiric acid increases the number of roots in the guava cuttings.
\end{abstract}

Index terms: IBA, propagation, Psidium guajava L., shading

\section{INTRODUÇÃO}

Com o desenvolvimento de sistemas de nebulização, tornou-se possível enraizar estacas que antes eram consideradas muito difíceis ou impossíveis de enraizar, como as de goiabeira. Para isso utilizam-se estacas de ramos com madeira parcialmente madura e que possuam folhas. Este tipo de estaca, com madeira ainda não lignificada, geralmente enraíza com maior rapidez, porém requer equipamentos apropriados e melhor controle dos fatores que afetam a formação de raízes adventícias. O controle destes fatores, associados à utilização de técnicas como, aplicação exógena de auxinas sintéticas e estiolamento de ramos, podem aumentar a capacidade de enraizamento de estacas caulinares de espécies como a goiabeira.

$\mathrm{O}$ efeito da aplicação exógena de auxinas sintéticas no enraizamento de estacas de goiabeira foi estudado por diversos autores. Pereira et al. (1991), estudando o efeito do AIB em estacas de goiabeira Rica e Paluma, observaram a ação positiva da auxina na precocidade da iniciação radicular e no maior número de raízes. Kersten \& Ibañez (1993) obtiveram resultados superiores com a utilização de AIB em imersão rápida, em estacas de goiabeira Kumagai, quando comparadas com a não utilização desta auxina.

A aplicação de auxina na base das estacas promove o enraizamento até uma determinada concentração, a partir da qual o efeito passa a ser inibitório (Hartmann et al., 1990). Bacarin et al. (1994) constataram, na cultivar Rica, que na aplicação de AIB em imersão lenta, a concentração de $100 \mathrm{mg} . \mathrm{L}^{-1}$ proporcionou maior porcentagem de enraizamento que $200 \mathrm{mg} . \mathrm{L}^{-1}$.

O comportamento de estacas de uma mesma espécie pode não ser o mesmo, pois as diferenças muitas vezes ocorrem entre cultivares. Tavares et al. (1995) verificaram que estacas retiradas de goiabeiras que produziam frutos vermelhos apresentavam enraizamento superior, quando comparadas com as de polpa branca.

No estudo do enraizamento de estacas, técnicas como o estiolamento de ramos podem ser aplicadas com a finalidade de induzir a formação de raízes. Os ramos estiolados apresentam diferenças anatômicas que podem favorecer o aparecimento de primórdios radiculares, assim como uma maior quantidade de células parenquimáticas e a diminuição das barreiras mecânicas. Além disso, pode favorecer a ação da auxina, uma vez que torna os tecidos mais sensíveis à ação deste regulador de crescimento (Hartmann et al., 1990). Figueiredo et al. (1995) utilizaram o estiolamento em partes dos ramos de estacas de goiabeira serrana (Feijoa sellowiana Berg.) durante 60 dias, obtendo um incremento significativo na porcentagem de estacas enraizadas. Observaram também um efeito fitotóxico na aplicação de AIB, uma vez que a porcentagem de enraizamento decresceu com o aumento da aplicação da auxina. Os autores atribuíram este fato à elevação da auxina endógena dos tecidos, provocada pelo estiolamento. Resultados semelhantes foram encontrados por Voltolini \& Fachinello (1997), em estacas de araçazeiro amarelo (Psidium cattleyanum Sabine) retiradas de plantas matrizes sob sombreamento de 30, 50 e $70 \%$.

Heller et al. (1994) constataram que o sombreamento moderado das plantas matrizes, da ordem de $50 \%$, proporcionou $90 \%$ de enraizamento de estacas da ornamental Coleonema aspalathoides, enquanto que estacas oriundas de matrizes em condições normais de luminosidade apresentaram $30 \%$ de enraizamento. Verificaram também que aumentando o sombreamento, 75 e 87,5\%, apresentaram resultados inferiores devido a menor quantidade de carboidratos nas estacas proporcionada pela diminuição na atividade fotossintética.

O objetivo do presente trabalho foi verificar o efeito do estiolamento da planta matriz e sua interação com a utilização de AIB no enraizamento de duas cultivares de goiabeira.

\section{MATERIALEMÉTODOS}

As estacas foram obtidas de plantas matrizes das goiabeiras Rica e Kumagai, de 5 anos de idade, que estão localizadas na área expe-

\footnotetext{
${ }^{1}$ (Trabalho 170/2002). Recebido: 12/09/2002. Aceito para publicacão: 23/05/2003.

${ }^{2}$ Eng. Agr. MSc. FMC, Campinas - SP. whcosta@uol.com.br.

${ }^{3}$ Eng. Agr. Professor Associado do Departamento de Produção Vegetal, USP/ESALQ, Caixa Postal 9, CEP 13418-900, Piracicaba, SP. jascarpa@ carpa.ciagri.usp.br.

${ }^{4}$ Eng $^{\text {a }}$. Agr ${ }^{\mathrm{a}}$. Doutoranda em Fitotecnia, Departamento de Produção Vegetal, USP/ESALQ, Caixa Postal 9, CEP 13418-900, Piracicaba, SP. dcbastos@esalq.usp.br.
} 
rimental do Departamento de Produção Vegetal da ESALQ/USP, em Piracicaba (SP). Durante o período de enraizamento (verão), as estacas foram mantidas em casa de vegetação sob nebulização intermitente, no Núcleo de Produção de Mudas da CATI, em Tietê (SP).

As plantas matrizes foram submetidas pelo período de 14 meses em condições de $30 \%$ e 50\% de sombreamento e em pleno sol. Após esse período foram coletados ramos semilenhosos (sub apicais), com "madeira verde", sem brotações laterais. À partir de segmentos destes ramos, contendo três nós e um par de folhas inteiras, foram preparadas estacas, de cerca de $20 \mathrm{~cm}$ de comprimento e 0,8 cm de diâmetro. Em seguida, foram submetidas ao tratamento com ácido indolbutírico nas concentrações de 0 e $2000 \mathrm{mg}$. $\mathrm{L}^{-1}$, aplicadas em imersão rápida, por um período de 5 segundos. As soluções foram obtidas mediante a diluição do AIB em álcool 50\%. Utilizaram-se bandejas plásticas, medindo 46,0 $\mathrm{cm} \times 9,0 \mathrm{~cm} \times 28,0 \mathrm{~cm}$, preenchidas com o substrato vermiculita de grânulos médios, no qual foram colocadas as estacas. Cada bandeja conteve 3 repetições, de diferentes tratamentos, dispostas a acaso, sendo que cada parcela foi composta por 10 estacas. Adotou-se o delineamento estatístico de blocos ao acaso, em fatorial 2 × 3, onde os fatores estudados foram concentração de AIB, em dois níveis $\left(0\right.$ e 2000 mg.L $\left.\mathrm{L}^{-1}\right)$, e sombreamento, em três níveis $(0,30$ e $50 \%)$.

Após 60 dias, avaliou-se a porcentagem de estacas enraizadas, o número de raízes por estaca, a porcentagem de estacas mortas e de estacas com gemas brotadas. Para efeito da análise estatística, os dados em porcentagem foram transformados em arco seno $(\mathrm{x} / 100)^{1 / 2} \mathrm{e}$ os demais em $(x+0,5)^{1 / 2}$.

\section{RESULTADOS E DISCUSSÃO}

Verifica-se (Tabela 1) que as cultivares de goiabeira Rica e Kumagai possuem diferentes capacidades de enraizamento. Observa-se no tratamento controle (0 mg. $\mathrm{L}^{-1}$ de AIB e $0 \%$ de sombreamento) as porcentagens de enraizamento de $60 \%$ para Rica e $14,94 \%$ para Kumagai. Pode-se classificar Rica como uma cultivar mais fácil de enraizar que Kumagai. Este resultado concorda com o encontrado por Tavares et al. (1995), que verificaram que estacas de goiabeiras que produziam frutos vermelhos apresentaram enraizamento superior, quando comparados com as de polpa branca.

TABELA 1 - Efeito do sombreamento e da aplicação de diferentes concentrações de AIB na porcentagem de enraizamento de estacas semilenhosas de goiabeira cultivares Rica e Kumagai.

\begin{tabular}{|c|c|c|c|c|}
\hline \multirow[t]{2}{*}{ Cultivares } & \multirow[t]{2}{*}{$\begin{array}{l}\text { Porcentagem de } \\
\text { sombreamento }\end{array}$} & \multicolumn{2}{|c|}{$\begin{array}{c}\text { Concentração de AIB } \\
\left(\mathrm{mg.L}^{-1}\right)\end{array}$} & \multirow[t]{2}{*}{ Médias } \\
\hline & & 0 & 2000 & \\
\hline \multirow{3}{*}{ Rica } & 0 & $60,00 \mathrm{~b} \mathrm{~B}$ & 97,27 a A & 82,98 \\
\hline & 30 & 89,71 a A & 97,27 a A & 94,06 \\
\hline & 50 & $75,17 \mathrm{ab} B$ & 95,35 a A & 86,96 \\
\hline $\mathrm{CV}(\%)$ & \multicolumn{4}{|c|}{10,75} \\
\hline \multirow{3}{*}{ Kumagai } & 0 & 14,94 b B & $57,63 \mathrm{~b} \mathrm{~A}$ & 34,46 \\
\hline & 30 & 71,09 a A & 85,35 a A & 78,66 \\
\hline & 50 & 56,73 a $\mathrm{A}$ & $50,00 \mathrm{~b} \mathrm{~A}$ & 53,37 \\
\hline CV $(\%)$ & \multicolumn{4}{|c|}{12,84} \\
\hline
\end{tabular}

As médias seguidas de mesma letra maiúscula na linha e minúscula na coluna não diferem entre si pelo teste de Tukey a nível de 5\% de probabilidade.

Pode-se verificar também que quando se utilizou as estacas retiradas de plantas submetidas ao sombreamento, estas apresentaram comportamento diferenciado daquelas cujas plantas matrizes encontravam-se a pleno sol. Para as cultivares Rica e Kumagai, os melhores resultados foram obtidos com estacas de plantas sombreadas em $30 \%$, obtendo-se respectivamente 89,71 e 71,09\% de enraizamento.

$\mathrm{O}$ melhor desempenho dessas estacas pode estar relacionado às maiores concentrações de auxinas endógenas nos ramos, provocada pelo sombreamento (Hartmann et. al., 1990; Voltolini \& Fachinello, 1997).

O sombreamento de 50\%, sem a utilização de AIB, influenciou de forma diferente as cultivares. Para a cultivar Kumagai, goiabeira que naturalmente apresenta maior dificuldade de enraizamento de estacas (Gonzales \& Schimidt, 1992), o sombreamento apresentou resultado significativamente superior ao controle, não apresentando diferença estatística significativa entre $30 \%$ e $50 \%$ de sombreamento. No entanto, para a cultivar Rica, $50 \%$ de sombreamento proporcionou um resultado intermediário, não diferindo estatisticamente dos outros tratamentos.

A aplicação de AIB, na concentração de $2000 \mathrm{mg} . \mathrm{L}^{-1}$, aumentou a porcentagem de enraizamento das duas cultivares, quando se utilizou estacas retiradas de plantas desenvolvidas em pleno sol (Tabela 1). Johnson \& Hamilton (1997) atribuíram o efeito do AIB aos baixos níveis de auxinas endógenas proporcionados pela fotoinativação e pela ação da AIA oxidase, enzima que degrada o AIA. Entretanto, quando utilizouse AIB (2000 mg.L $\mathrm{L}^{-1}$ ) em estacas retiradas de plantas sombreadas, as cultivares testadas tiveram comportamento diferentes. Para a cultivar Kumagai, a aplicação de AIB não aumentou a percentagem de enraizamento em estacas de ramos crescidos em 30 e $50 \%$ de sombreamento. Para esta cultivar, o AIB teve um efeito supressivo nas estacas estioladas em $50 \%$ de sombreamento, ficando significativamente inferior à percentagem de estacas enraizadas com $30 \%$ de sombreamento. De acordo com Hartmann et al. (1990), o estímulo ao enraizamento ocorre até uma determinada concentração de auxina, à partir da qual o efeito passa a ser inibitório.

A baixa porcentagem de enraizamento obtido de estacas estioladas em plantas com 50\% de sombreamento, teoricamente pode estar relacionada à maior disponibilidade de auxinas endógenas. Logo, a maior disponibilidade de auxinas nos tecidos destas estacas, associada à aplicação de $2000 \mathrm{mg} . \mathrm{L}^{-1}$ de AIB, podem ter proporcionado a diminuição do enraizamento. Resultados semelhantes foram observados em goiabeira serrana (Figueiredo et al., 1995) e araçazeiro amarelo (Voltolini \& Fachinello, 1997)

Esta teoria porém, não explica os resultados obtidos para a cultivar Rica (Tabela 1), que com a aplicação de AIB, aumentou o enraizamento de estacas estioladas com $50 \%$ de sombreamento. Isto sugere que outros fatores devem estar relacionados, além das concentrações de auxinas, na performance de enraizamento de estacas estioladas.

Portanto, para a cultivar Kumagai, de difícil enraizamento, o sombreamento de $30 \%$ nas plantas matrizes mostrou ser o melhor tratamento para aumentar a porcentagem de estacas enraizadas, enquanto que para a cultivar Rica, de fácil enraizamento, estacas estioladas com $30 \%$ de sombreamento ou aplicação de AIB na concentração de 2000 mg. $L^{-1}$ apresentaram os melhores resultados. Estes resultados são concordantes com Figueiredo et al. (1995) que consideraram desnecessário a utilização de AIB no enraizamento de estacas estioladas de goiabeira serrana.

A Tabela 2 apresenta as médias de raízes formadas nas estacas para as duas cultivares. Verifica-se que para a cultivar Rica, tanto o sombreamento das plantas matrizes, como a utilização de AIB, favoreceram a formação de um maior número de raízes. As maiores médias de raízes formadas foram obtidas com sombreamento de 30 e $50 \%$ mais a utilização de AIB. A capacidade do AIB de estimular a formação de raízes em goiabeira já foi verificada por diversos autores (Pereira et al., 1991; Kersten \& Ibañez, 1993; Bacarin et al., 1994).

Com relação ao número de raízes formadas em estacas que sofreram estiolamento, a resposta parece estar relacionada com a espécie ou cultivar. Maynard \& Bassuk (1996) verificaram que em estacas de Carpirus betulus, o número de raízes formadas aumentou até a utilização de $75 \%$ de sombreamento. Os autores constataram um maior número de fendas no anel de esclerênquima das estacas estioladas, as quais foram relacionadas ao maior número de raízes formadas. De outra forma, Voltolini \& Fachinello (1997) verificaram que estacas estioladas de araçazeiro amarelo não apresentaram diferenças significativas com relação ao número de raízes formadas, quando submetidas ao sombreamento de $0,30,50$ e $70 \%$. Isto também foi observado na cultivar Kumagai, onde pode-se constatar que o estiolamento não provocou aumento na média de raízes formadas (Tabela 2). Nesta cultivar, somente a utilização de AIB teve influência na quantidade de raízes formadas por estaca. 
TABELA 2 - Efeito do sombreamento e da aplicação de diferentes concentrações de AIB no número de raízes de estacas semilenhosas de goiabeira cultivares Rica e Kumagai.

\begin{tabular}{|c|c|c|c|c|}
\hline \multirow[t]{2}{*}{ Cultivares } & \multirow{2}{*}{$\begin{array}{l}\text { Porcentagem de } \\
\text { sombreamento }\end{array}$} & \multicolumn{2}{|c|}{$\begin{array}{c}\text { Concentração de AIB } \\
\left(\mathrm{mg.L}^{-1}\right)\end{array}$} & \multirow[t]{2}{*}{ Médias } \\
\hline & & 0 & 2000 & \\
\hline \multirow{3}{*}{ Rica } & 0 & 6,34 & 13,94 & $9,79 \mathrm{~b}$ \\
\hline & 30 & 9,20 & 21,40 & $14,69 \mathrm{ab}$ \\
\hline & 50 & 12,80 & 19,59 & $16,02 \mathrm{a}$ \\
\hline Médias & & $9,27 \mathrm{~B}$ & $18,17 \mathrm{~A}$ & \\
\hline CV (\%) & \multicolumn{4}{|c|}{16,40} \\
\hline \multirow{3}{*}{ Kumagai } & 0 & 1,35 & 7,61 & $3,93 \mathrm{a}$ \\
\hline & 30 & 2,07 & 6,80 & $4,14 \mathrm{a}$ \\
\hline & 50 & 1,00 & 5,98 & $3,05 \mathrm{a}$ \\
\hline \multirow{2}{*}{$\begin{array}{l}\text { Médias } \\
\text { CV }(\%)\end{array}$} & & $1,45 \mathrm{~B}$ & $6,78 \mathrm{~A}$ & \\
\hline & \multicolumn{4}{|c|}{15,30} \\
\hline
\end{tabular}

As médias seguidas de mesma letra maiúscula na linha e minúscula na coluna não diferem entre si pelo teste de Tukey a nível de 5\% de probabilidade.

Nas Figuras 1 e 2 verifica-se que houve diferenças no local de formação de raízes adventícias entre estacas estioladas e não estioladas, nas duas cultivares testadas. Nas estacas estioladas, as raízes formaramse quase que exclusivamente na região nodal, enquanto que nas estacas retiradas de plantas crescidas em pleno sol, a formação de raízes ocorreu tanto na região nodal como na internodal. A não formação de raízes na região internodal de estacas estioladas, pode estar relacionada à baixa concentração de carboidratos neste local. Heller et al. (1994) constataram que o sombreamento proporciona diminuição na atividade fotossintética e consequentemente prejudica a síntese de carboidratos, influenciando de forma negativa o enraizamento de estacas. A concentração de raízes formadas na região nodal de estacas estioladas, pode influenciar na qualidade da muda e consequentemente no desenvolvimento desta no campo, principalmente com relação à fixação no solo. Portanto, sugere-se que sejam feitos estudos posteriores para avaliar o desenvolvimento no campo destes tipos de mudas e seu comportamento com relação à fixação.

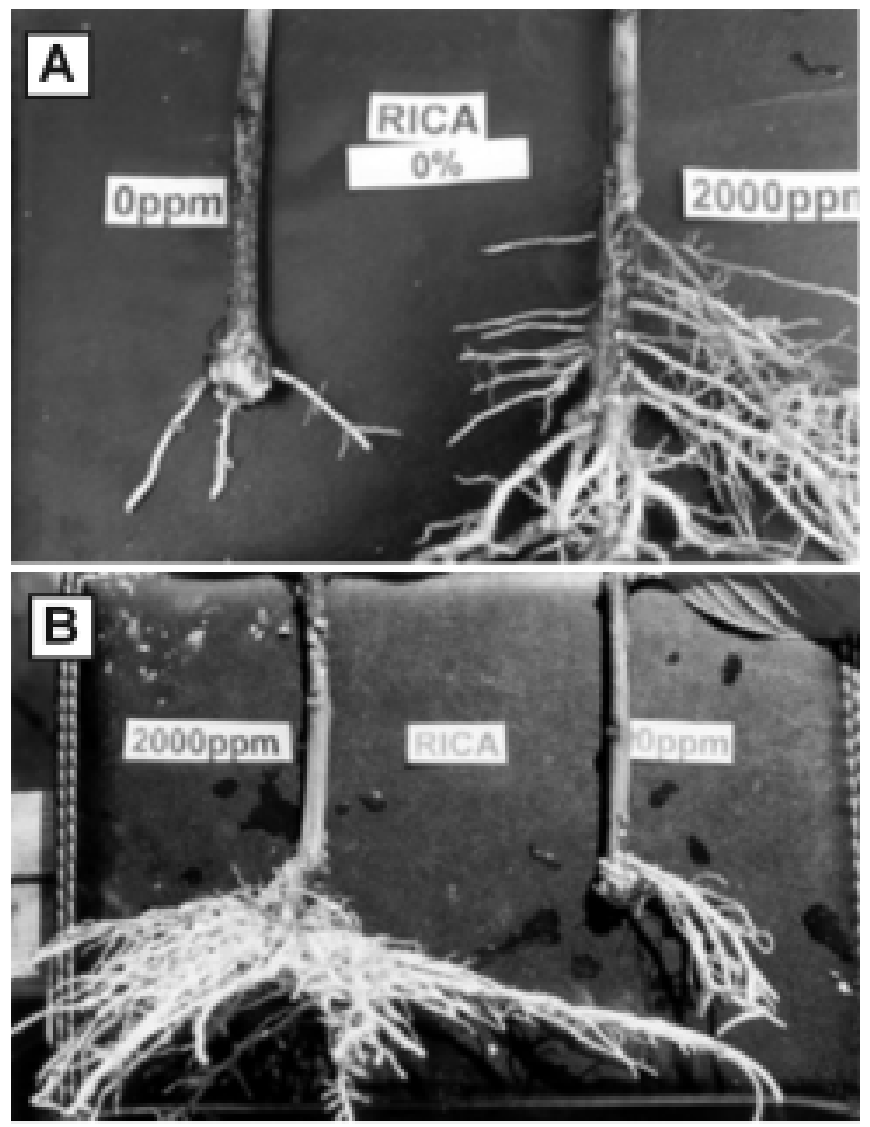

FIGURA 1 - Estacas de goiabeira Rica. (A) sob pleno sol; (B) sob 50\% de sombra.

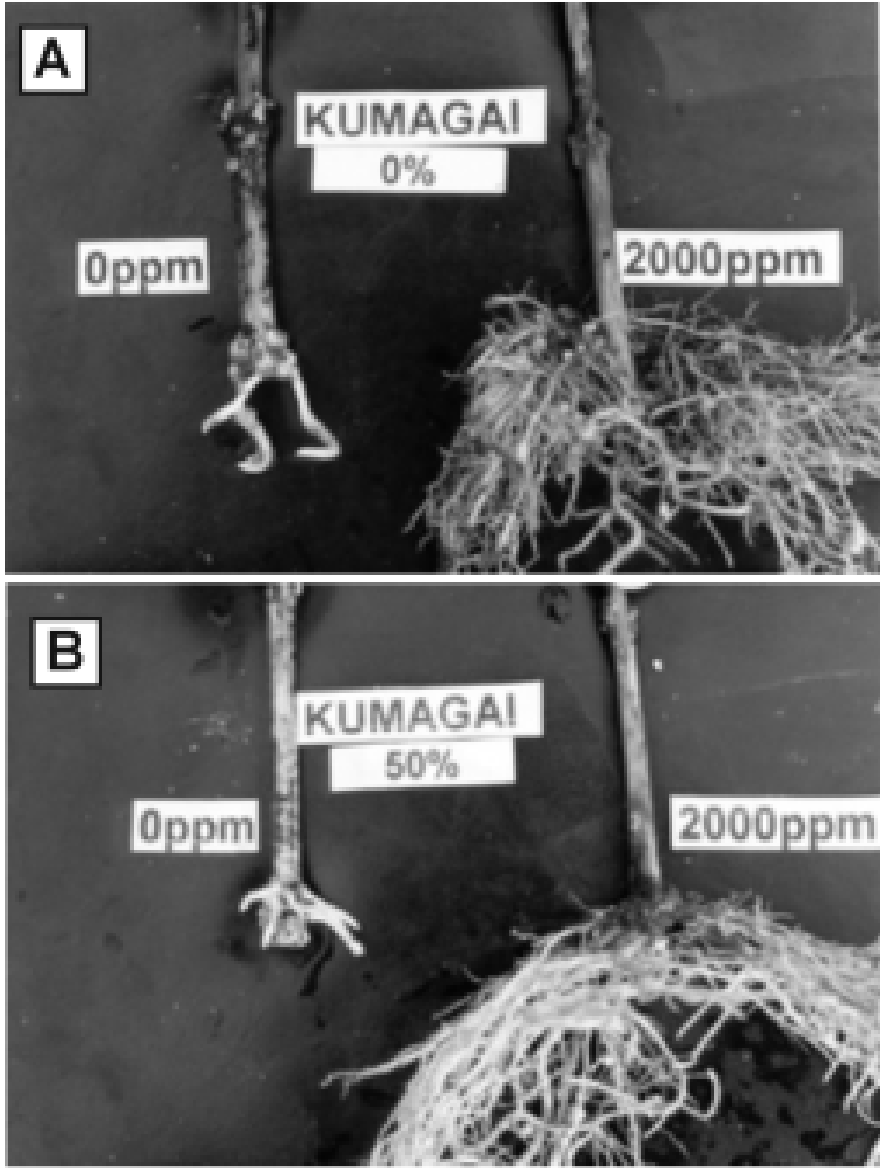

FIGURA 2 - Estacas de Goiabeira Kumagai. (A) sob pleno sol; (B) sob $50 \%$ de sombra.

A porcentagem de estacas mortas, assim como a de estacas brotadas, não foi significativa em nenhum dos tratamentos, para nenhuma das cultivares estudadas.

\section{CONCLUSÕES}

1) As cultivares testadas possuem diferentes capacidades de enraizamento.

2) Para a cultivar Kumagai, os melhores resultados de enraizamento foram observados com a utilização de $30 \%$ de sombreamento. Para a cultivar Rica, os melhores resultados de enraizamento foram observados com a utilização de $30 \%$ de sombreamento na planta matriz ou com a aplicação de $2000 \mathrm{mg} . \mathrm{L}^{-1} \mathrm{de}$ AIB na estaca.

3) A utilização de AIB aumentou o número de raízes formadas em estacas de goiabeira.

\section{REFERÊNCIASBIBLIOGRÁFICAS}

BACARIN, M.A.; BENINCASA, M. M. P.; ANDRADE, V. M. M.; PEREIRA, F. M. Enraizamento de estacas aéreas de goiabeira (Psidium guajava L.): Efeito do ácido indolbutírico sobre a iniciação radicular. Científica, São Paulo, v.22, n.1, p.71-79, 1994.

FIGUEIREDO, S.L.B.; KERSTEN, E.; SCHUCH, M.W. Efeito do estiolamento parcial e do ácido indolbutírico no enraizamento de estacas de ramos de goiabeira serrana (Feijoa sellowiana, Berg). Scientia Agricola, Piracicaba, v.52, n.1, p.167-171, 1995.

GONZÁLES, M.G.N.; SCHIMIDT, C.A.P. Estudo do efeito de duas concentrações de ácido indol butírico e ácido naftaleno acético no enraizamento de estacas herbáceas de goiabeira (Psidium guajava L.) cv. Kumagai. Revista Brasileira de Fruticultura, Cruz das Almas, v.14, n.3, p.229-232, 1992.

HARTMANN, H.T.; KESTER, D. E.; DAVIES, JR, F.T. Plant propagation: principles and pratices. 5. ed. New Jersey: Prentice Hall, 1990. 647p. 
HELLER, A.; BOROCHOV, A.; HALEVY, A.H. Factors affecting rooting ability of Coleonema aspalathoides. Scientia Horticulturae, Amsterdam, v.58, p.335-341, 1994.

JOHNSON, C.R.; HAMILTON, D.F. Rooting of Hibiscus rosa-sinensis L. cuttings as influenced by light intensity and ethephon. HortScience, Alexandria, v.12, n.1, p.39-40, 1997.

KERSTEN, E.; IBAÑEZ, U.A. Efeito do ácido indolbutírico no enraizamento de estacas de ramos de goiabeira (Psidium guajava L.) em condição de nebulização e teor de aminoácidos totais. Revista Brasileira de Fruticultura, Cruz das Almas, v.15, n.1, p.87-89, 1993.

MAYNARD, B.K.; BASSUK, N.L. Effects of stock plant etiolation, shading, banding, and shoot development on histology and cutting propagation of Carpirus betulus L. fastigiata. Journal of Ameri- can Society for Horticultural Science, Madison, v.121, n.5, p.853860, 1996.

PEREIRA, F. M.; PETRECHEN, E.H.; BENINCASA, M. M. P.; BANZATTO, D. A. Efeito do ácido indolbutírico no enraizamento de estacas herbáceas de goiabeira (Psidium guajava L.) das cultivares 'Rica' e 'Paluma', em câmara de nebulização. Científica, Jaboticabal, v.19, n.2, p.199-206, 1991.

TAVARES, M. S. W.; KERSTEN, E.; SIEDWERDT, F. Efeitos do ácido indolbutírico e da época de coleta no enraizamento de estacas de goiabeira (Psidium guajava L.). Scientia Agricola, Piracicaba, v.52, n.2, p.310-317, 1995.

VOLTOLINI, J.A.; FACHINELLO, J.C. Effect of shading cattley guava stock plant (Psidium cattleyanum Sabine) on propagation by cuttings. Acta Horticulturae, Wazeninzen, v.452, p.59-62, 1997. 